Accepted manuscript (post-peer-reviewed, pre-copyedit). To appear in

Philosophical Psychology. Please do not cite this version.

\title{
ECOLOGICAL PSYCHOLOGY IS RADICAL ENOUGH. A REPLY TO RADICAL ENACTIVISTS
}

\author{
Miguel Segundo-Ortin1,*, Manuel Heras-Escribano² \& Vicente Raja ${ }^{3}$ \\ ${ }^{1}$ School of Humanities and Social Inquiry, Faculty of Law, Humanities, and the Arts, \\ University of Wollongong, Australia" \\ ${ }^{2}$ IAS Research Centre for Life, Mind, and Society; Department of Logic and Philosophy of \\ Science, University of the Basque Country, Spain \\ ${ }^{3}$ Rotman Institute of Philosophy, Western University, Canada \\ * Corresponding author: \\ E-mail: miguel.segundo.ortin@gmail.com \\ School of Humanities and Social Enquiry \\ Faculty of Law, Humanities and the Arts \\ Univertisity of Wollongong (Australia)
}

\begin{abstract}
Ecological psychology is one of the most influential theories of perception in the embodied, anti-representational, and situated cognitive sciences. However, radical enactivists claim that Gibsonians tend to describe ecological information and its 'pick up' in ways that make ecological psychology close to representational theories of perception and cognition (Myin 2016; Hutto 2017; Hutto and Myin 2017; see also van Dijk et al. 2015). Motivated by worries about the tenability of classical views of informational content and its processing, these authors claim that ecological psychology needs to be "RECtified" so as to explicitly resist representational readings. In this paper, we argue against this call for RECtification. To do so, we offer a detailed analysis of the notion of perceptual information, and other related notions such as specificity and meaning, as they are presented in the specialized ecological literature. We defend that these notions, if properly understood, remain free of any
\end{abstract}


representational commitment. Ecological psychology, we conclude, does not need to be RECtified.

Keywords: Ecological psychology, Radical enactivism, Information, Affordances, Meaning, Specificity.

\section{Introduction}

Ecological psychology, hereafter EP, is usually characterized by its stark opposition to representational and computational theories of perception (Gibson 1979/2015; Michaels and Carello 1981; Turvey et al. 1981; Chemero 2009). According to the ecological approach, perception requires neither the manipulation of contents nor the formation of mental representations of the world. Instead, perception is said to consist of the detection of specifying information.

The principles of EP have been combined with other theoretical tools, namely Dynamical Systems Theory, to give birth to radical embodied cognitive science (Chemero 2009; see also Richardson et al. 2008). Radical embodied cognitive science is an explanatory framework that aims to account for different cognitive processes without positing representational states and computational processes.

Despite agreeing about the benefits of non-representational approaches, radical enactivists are reluctant about embracing EP without reservation (Myin 2016; Hutto 2017; Hutto and Myin 2017; see also van Dijk et al. 2015). Radical enactivists give stronger and weaker reasons for this reticence. Sometimes they accuse proponents of EP of using language that encourages or, at least, makes it susceptible to representationalist readings. A much stronger claim is that EP advances an account of perception that is akin to the one offered by representationalists. Those who press the stronger complaint argue that to describe perceptual information as being meaningful and specific entails an underlying commitment to the existence of informational content in the external 
world. In light of this, radical enactivists conclude that EP is not radical enough as it stands, and that it needs to be "RECtified"-viz., purged of its representational commitments-before it can be included in a genuine nonrepresentational approach to cognitive science.

In this paper, we argue against this call for RECtification. We offer a detailed analysis of the notion of perceptual information, and other related notions such as specificity and meaning, as they are presented in the specialized Gibsonian literature. We defend that the use of these notions does not entail a commitment to a contentful notion of information and, thus, that EP is not in conflict with the principles of the radical forms of embodied, nonrepresentational cognitive science. ${ }^{1}$

The action of the paper proceeds as follows. Section one offers a general description of EP. Section two reviews the main arguments of radical enactivists for being reticent about EP, all of which target the notions of information, specification, and meaning. According to the stronger complaint advanced by radical enactivists against EP, Gibsonians are committed to the thesis that there is informational content in the world. We offer a two-pronged counterargument. Section three makes the first part of the argument, analyzing the notion of information as used in EP. We argue that information, as conceived of by Gibsonians, is not just "out there" and independent of organisms. Rather, ecological or specifying information is always for organism-environment systems. Section four supplies the second part of the argument, addressing the notions of specificity and meaning. First, we argue that specificity refers to the lawful, unique relation holding between environment, information, and perception. This specifying relation, we suggest, can best be understood in terms of covariation, without any assumption that it carries content. Second, we argue that ecological information is meaningful because it affords agents the

\footnotetext{
1 Please, note that our claim is not that EP is logically incompatible with a representational account (see Golonka and Wilson (2016) for a discussion of this possibility). Rather, our claim is that such interpretation is not implied by the theory itself. Thanks to an anonymous reviewer for the pointer.
} 
possibility of performing certain actions, and, thus, that the notion of meaning as used in EP is orthogonal to semantics.

Hence, we conclude, the notions of information, specificity, and meaning, as used by Gibsonians, are free of any commitment to contents and representations. Therefore, EP does not need to be RECtified.

\section{A Primer on Ecological Psychology}

Arguably, the most notable feature of EP is its stark opposition to constructivist theories of perception. Constructivist theories, broadly construed, assume that stimulus information is ambiguous and impoverished, and that perception requires the internal enrichment and disambiguation of the sensory data by the organism. These perceptual processes, in addition, are thought to involve the computation of representations, and conclude with the construction of an image of the external world in the brain (Ullman 1980; Fodor and Pylyshyn 1981; Marr 1982).

In arguing against constructivism, Gibsonians usually subscribe to three interrelated theses: First, that perception is direct; second, that perception is active; and, third, that perception is action-oriented (Michaels and Carello 1981; Chemero 2009; Heras-Escribano and de Pinedo 2016).

First of all, EP rejects the assumption that stimulus information is impoverished. Instead, Gibsonians argue that stimulation can be informationally rich and unambiguous, and thus that agents can perceive the environment directly-without internal computation or processing-by detecting or picking up this information.

Second, EP breaks with the traditional picture of perception as a passive, sub-personal process that occurs inside the animals' brains. By contrast, Gibsonians understand perception as a kind of activity, a process that involves the goal-oriented exploration of the surroundings by the agent. Accordingly, perception occurs in the context of the dynamic sensorimotor interactions between the agent and the environment-the so-called perception-action loops. 
A consequence of this thesis is that the perceptual systems of an organism cannot be reduced to its sensory organs and its brain only. Instead, perceptual systems are thought to include its whole body and its actions (Gibson 1966, 1979/2015; Glotzbach and Heft, 1982; Stoffregen et al. 2017).

The last thesis is that perception is action-oriented. According to Gibsonians, the primary goal of perception is not the construction of internal images of the external world but the successful control of action. In Gibson's words: "perception serves behavior, and behavior is controlled by perception" (1979/2015, p. 213). To explain how perception can serve the control of the action, Gibsonians hypothesize that the primary objects of perception are affordances-the opportunities for interaction that an environment offers to an organism.

One might be tempted to conclude, from the above, that perception involves two different processes according to EP-the detection of information, on the one hand, and the perception of an affordance, on the other. However, this would be a mistake. According to EP, these processes are the same: detecting information is perceiving affordances. When I see the mug on my desk, for example, I perceive the possibility of grasping it, and I can coordinate my actions to that goal by relying on the perceptual information I detect.

In summary, EP promises an explanation of perceptually guided intelligent behavior that does not posit mental representations. According to EP, agents do not need to represent the environment in order to perceive and act upon the affordances available in it; instead, they coordinate their interaction with the surroundings by detecting information.

The principles of EP have inspired different research programs in nonrepresentational cognitive science (see, e.g., Chemero 2009; Richardson et al. 2008; Gibson and Pick 2000). However, not all advocates of nonrepresentationalism are so optimistic about embracing EP. The following section reviews the arguments offered by radical enactivists (Hutto and Myin 2017; Hutto 2017; Myin 2016). These arguments conclude that EP lends itself to 
positions that are incompatible with a non-representational approach to cognitive science.

\section{Radical enactivism meets ecological psychology}

Radical enactivism, hereafter REC, is a promising new line of thought in the current debates on the philosophy of mind and cognitive science (Hutto and Myin 2013, 2017). Having its roots in classical enactivism (Varela et al. 1991; Thompson 2007), the core hypothesis of REC is that the fundamental forms of cognition-that is, those at the roots and basis of cognition-are noncontentful. ${ }^{2}$

According to Hutto and Myin, a given state or process has content if and only if it has conditions of satisfaction of a particular sort, namely, if it can be true or false, correct or incorrect, accurate or inaccurate, veridical or nonveridical, etc., regarding something else (2013, p. x). ${ }^{3}$ Traditionally, they argue, most theories in cognitive science have assumed that mental representations are contentful in these terms, and that the manipulation of such contentful states or representations is a necessary condition for organisms to behave intelligently or cognitively.

Against this tendency, REC states that cognition is, at its basis, "a matter of sensitively and selectively responding to information, but it does not involve picking up and processing information or the formation of representational contents" (Hutto and Myin 2017, p. 92). If REC is on the right track, organisms can engage in sophisticated, world-directed cognitive activities in ways that can be adequately explained by appeal to nothing more than their sensitivity and responsiveness to the information available in the environment.

\footnotetext{
2 Hutto and Myin use "basic cognition" to refer to the cognitive capacities that are shared across species and that are both ontogenetically and phylogenetically prior to sociocultural scaffolding. These basic cognitive abilities include "central forms of human cognition, such as perceiving, imagining, and remembering both in children and adults" (2017, p. 90).

${ }^{3}$ In what follows, we will stick to this notion of content. We argue that the kind of information that EP invokes does not include such features.
} 
Yet, as Hutto (2017) emphasizes, we should not see REC as a new, alternative version of enactivism that tries to develop its own explanatory tools. Instead, REC aims to take elements from the enactivist tradition and combine them with other existing theories to form a global, non-representational approach to cognitive science.

One of the theories that have attracted the attention of radical enactivists is EP. However, despite the substantive points of agreement holding between both approaches, radical enactivists are skeptical about the possibility of incorporating EP into a non-representational approach to cognitive science. In summary, Hutto and Myin raise three main concerns about EP. First, they are concerned about the idea that perception involves picking up information from the external world. Second, they worry about the idea that this information specifies or is about the environment and the affordances present within. And, finally, they object to the idea that this information is meaningful. As expressed by Hutto (2017), the fact that EP relies on these "semantic-friendly notions" reveals "an underlying commitment to an information-processing story that is inconsistent with nonrepresentationalist accounts of mind and cognition" (2017, p. 383; see also Hutto and Myin 2017, pp. 82-88).

Myin (2016) has offered stronger complaints about EP. According to him:

[I]n proposing this account of direct perception, and arguably in the very assumption of invariant properties, some Gibsonian theorists have been driven to a position [...] which appears to propose externalist, worldinvolving instead of brain-involving, versions of cognitivist posits. In particular, Gibsonians theorists have described invariants in what are essentially semantic terms, namely invariants as being about the environment or affordances, where affordances are understood as action possibilities. (p. 97, emphasis added)

To support his argument, Myin draws on the analysis of van Dijk et al. (2015) about the historical evolution of Gibson's notion of information. According to van Dijk and colleagues, in his early works, Gibson conceived of the 
ambient optic array ${ }^{4}$ as being contentful-as being true or false, correct or incorrect, and so on, with regards to the external world (Gibson 1961).

Although Gibson's later work $(1966,1979)$ is seen by van Dijk and colleagues (2015) as an attempt to break away with the idea that information in the ambient array carries content about the environment, they do not think that this attempt is successful. For them, the contentless account of information pursued by Gibson does not sit well with the fact that Gibson and most Gibsonians conceive of perceptual information as being grounded "in environmental specification" (p. 212), keeping on the idea that information is about the environment. This emphasis on specification, they argue, "makes it hard to get a content-less reading of even the most progressive ecological theories" (p. 212).

Myin (2016) raises worries on this score. As he states, the fact that most Gibsonians stick to the use of notions such as 'specificity,' 'aboutness,' or 'meaning' - that is, notions that belong "to the semantic sphere, or to the language with which content-carrying representations are characterized" (p. 98)-when describing the invariant patterns of the array shows that EP conflates perceptual information with information of a contentful kind. Thus, he concludes, Gibsonians fall prey to a view of perception that is akin to the one offered by representationalists:

For all the intended and real differences, there is something common to talking about invariants and affordances in terms of specification (understood as description) and a cognitivist outlook. In both cases, perceptual experience gets explained in terms of something that already carries content or has meaning. (pp. 97-98)

Two consequences follow from Myin's analysis. First, EP, as it stands, cannot be reconciled with a radical embodied, non-representational theory of cognition. Indeed, he writes, "[EP] holds on to the main characters of the cognitivist picture, content-carrying vehicles, locating these in the outside world

\footnotetext{
4 The phenomenon of all reflections and refractions of light on the surfaces of the environment generates what Gibson dubs the "ambient optic array" (see Gibson, 1979/2015, Ch. 5).
} 
instead of the head" (p. 98), thus remaining very conservative within the spectrum of the theories of embodied cognition.

Second, if EP commits to a notion of contentful information, it suffers from the same theoretical flaws as any other representational theory of cognition. According to Hutto and Myin, the only naturalistic theory of information currently available is information-as-covariance. According to this notion, a state of affairs $A$ (e.g., the number of rings in a trunk) is said to carry information about another state of affairs $B$ (e.g., the age of the tree) if and only if the occurrence of both states $A$ and $B$ covary lawfully, or reliably enough.5 This relation of covariance, however, is logically distinct to a contentful relation, meaning that information-as-covariance is not by itself information-as-content. It follows from this logical distinction that if we only have a naturalistic account of the former, "we have, as yet, no explanation for the natural occurrence of informational contents in the world" (Hutto and Myin 2013, p. 71). Hutto and Myin (2013) refer to the lack of a naturalistic account for the existence of content as the "Hard Problem of Content."

Thus, in so far as Gibsonians commit to the existence of informational content in nature, they fall prey to the same dilemma as their representationalist cousins. ${ }^{6}$ They can either offer a new notion of information, one that satisfies the

\footnotetext{
${ }^{5}$ Hutto and Myin (2013, p. 66) borrow this example from Jacob (1997, p. 45), and present it as a genuine instance of covariant information (for subsequent uses of this example see Hutto and Myin 2017, p. 30). An anonymous reviewer, by contrast, points out that covariant information is more technically referred to as Shannon information (Shannon 1948), whereas this example refers to what Grice dubs "natural meaning" (1957). We thank the reviewer for the pointer. However, we prefer to remain neutral with regards to this discussion and to describe the notion as Hutto and Myin present it.

${ }^{6}$ Although Hutto and Myin present the Hard Problem of Content as a general problem for representationalism in cognitive science, they examine different possible options to solve it. According to them, the most promising strategy is Millikan's teleosemantics (Millikan, 1984, 2005), which appeals to biological teleofunctions as derived from natural selection to explain content. The advantage of this approach is that it does not commit to the existence of representational contents in nature that need to be gathered via the senses. Instead, for teleosemanticists content-related properties are (partly) given by the interpretive activity of the system. The guiding idea of teleosemantics is that a device or an internal state $S$ has the teleofunction of representing $\mathrm{X}$ if it is used (interpreted, consumed) by the system because $\mathrm{S}$ has the proper function of indicating the presence of X. This, however, is not enough to naturalize content. As Hutto and Myin argue, even though appealing to biological teleofunctions can serve to describe biological norms, they do not suffice to account for the kind of normativity implied by 
criteria for being contentful while remains consistent with the natural sciences, or give up to any commitment to information-as-content when explaining perception.

Two main proposals have been advanced in order to purge EP of its representational commitments. Both proposals require abandoning the idea that patterns in the ambient array specify the environment and the affordances present in it.

The first one has been offered by van Dijk et al. (2015), and it is known as the "usage-based account." According to this proposal, information only comes into play as an individual uses the patterns in the ambient array to deal with the environment. As they write, "ecological information needs not be about anything-has no "aboutness"-prior to its use" (p. 213). As they argue, it is only by assuming that these patterns do not contain information independently of being used that we can break away with the idea that they are contentful: "from such a perspective there is no information in content, but only in use" (p. 213).

The second one is the one advanced by Myin (2016). Instead of active usage, Myin emphasizes the organisms' history of interactions to explain how the patterns can relate to the environment and the affordances without mediating content. According to this view, successful interactions generate patterns of sensitivity and reaction to similar worldly offerings. These acquired patterns determine the organism's current relationship with its environment, and provide the basis on which new action-perception patterns can emerge:

Environmental properties don't by themselves specify 'that something can afford this or that.' But an organism that has a history of interactions with those properties can have found out that this or that action was actually afforded in the past, and that can be the basis on which its current

content-such as the property of misrepresenting $\mathrm{X}$ or being wrong regarding $\mathrm{X}$. For instance, determining that a given state $S$ in the visual system of frogs has the function of indicating the presence of flies does not suffice to determine under what description this state represents flies-i.e., whether it represent them as "flies," as "moving dots," as "food," etc. It follows that "[e]ven if we can specify what is meant to be targeted [by the state S] that would give us no reason to think that the targeted item [the fly] is represented in a truth-conditional, referential, or otherwise semantic way" (2013, p. 80). 
perception of its environment can have become sensitive to these environmental properties. (2016, p. 99, emphasis original)

Once the history's role is properly understood, Myin writes, "there's no longer a need to describe environmental variables as themselves 'specifying' or 'describing' other properties' (p. 99). By going this direction, we can offer a theory that accounts for the animals' perception of affordances without appealing to contentful relations such as the ones allegedly implied by the notions of specification and meaning. Such "RECtified" version of EP is apt to be integrated into a radical embodied enactive account of cognition.

In what follows, we argue that the analyses offered by Myin (2016) and Hutto (2017), as well as the one offered by van Dijk et al. (2015), are misguided. Our aim is to show that describing ecological information as being specific and meaningful does not entail that this kind of information is contentful. Prior to that, however, we account for the nature of information posited by Gibsonians.

\section{Information at the ecological scale}

To understand what Gibsonians mean by information we need first to account for the distinction they make between stimulus and stimulus information. As Gibson famously argues, "[s]timulation may be a necessary condition for seeing, but it is not sufficient. There has to be stimulus information available to the perceptual system, not just stimulation of the receptors" (1979/2015, p. 49; see also Gibson 1966, p. 48).

To illustrate this distinction, Gibson offers the following example (1979/2015, pp. 59-62; Chemero 2009, pp. 107-108). Imagine an agent inside an illuminated room. Imagine, too, that we fill the room with a dense fog. For Gibson, visual perception is impossible in this situation. The reason is that even though there is still light in the room, the fog precludes it from reflecting and refracting on the walls and the objects that furnish the room, thereby preventing the ambient optic array to get structured. This lack of structure entails a lack of visual information. Therefore, even though there is light in the room to stimulate 
the agent's retina, it "cannot inform the subject about the surfaces in the room" (Chemero 2009, p. 107), making perception impossible.

This (perhaps simplistic) example allows us to formulate a preliminary characterization of what stimulus information is, according to EP. Stimulus information can be understood in terms of the relationship between the energy of a medium-i.e., light, vibrations, etc.-and the substances and surfaces of the objects this energy interacts with. Due to the interaction between the light and the objects of the room, for example, the optic array gets structured, and insofar as this structure corresponds to the structure of the surroundings, the former can be said to specify or 'contain' information about the latter. In this sense, stimulus information is said to be "a real, unproblematic aspect of the environment" (Chemero 2009, p. 108).

Nevertheless, it is precisely this characterization of information as being based on "[e]nvironmental correspondence alone" (van Dijk et al. 2015, p. 211) that motivates the worries of radical enactivists that specifying information smuggles in content. ${ }^{7}$ In what follows, we argue that this characterization captures only one part of the story, and that it needs to be complemented by appealing to the organisms. Once the role of the organism is properly understood, we can start seeing how the notion of information as used in EP breaks away from the notion of content.

One of the core assumptions of EP is that psychological or cognitive phenomena occur along temporally-extended processes in which agent and environment interact, reciprocally affecting each other. This assumption leads Gibsonians to reject the possibility of taking organism and environment as separate areas of inquiry, explaining cognition by focusing on one side alone. Instead, organism and environment are taken to be mutual, this is, as forming

\footnotetext{
${ }^{7}$ van Dijk et al. (2015) trace this criticism back to the work of Varela et al. (1991). As they explain: "They worried that the ecological notion of information that grounded information in the correspondence between the structure of ambient light and the environment, required too little participation of the animal. Environmental correspondence alone could not guarantee that ecological information allowed for perception without mediating content, and the process of information pick up did not alleviate trafficking content" (van Dijk et al. 2015, p. 211).
} 
"an inseparable pair" (Gibson 1979/2015, p. 4) or a single ecological unit-the organism-environment (O-E) system (Michaels and Carello 1981; Lombardo 1987; Favela and Chemero 2016). Several key concepts follow from adopting this ecological stance, including the notion of information that we discuss in this section, but also the notions of specificity and meaning.

In light of this O-E mutuality, in the first pages of The Ecological Approach to Visual Perception, Gibson (1979/2015) establishes a neat distinction between what he calls the "physical world" and the "environment." As he states, "[t]he physical world encompasses everything from atoms through terrestrial objects to galaxies. [...] Neither of these extremes is an environment" (p. 4). Since psychology is the study of the O-E systems, he argues, psychologists are not interested in the physical world, but in the surroundings as sized to the scale of the organisms that inhabit them. The environment as conceived of by EP is hence distinct from the world, as it appeals to the surroundings when taken in relation to what the organisms can detect and interact with. This environment can best be referred to as a habitat or an econiche:

We are concerned here with things at the ecological level, with the habitats of animals and men, because we all behave with respect to things we can look at and feel, or smell and taste, and events we can listen to. The sense organs of animals, the perceptual systems, the perceptual systems [...] are not capable of detecting atoms and galaxies. (Gibson 1979/2015, p. 5)

Once we take into account the special meaning that 'environment' has for Gibsonians, claims that information can be found in the environment acquire a new dimension. If the environment is to be taken in relation to the organisms, so does the information this environment 'contains.' Information, Gibson (1979/2015, p. 132) explains, "points two ways," to the organism and to the environment. We agree with Baggs and Chemero (2018) that this bidirectionality admits different readings, depending on whether we understand the organism as species or as an individual. ${ }^{8}$

\footnotetext{
8 According to Baggs and Chemero (2018), to the distinction between physical world and environment we must add the distinction between environment and "umwelt." As they point out:
} 
Regarding the first interpretation-organism as species-we argue that because different physical patterns require specialized perceptual systems capable of detecting them, a pattern that is informational for a kind of organism may not be so for another. For instance, whereas sharks can detect electric fields, humans cannot, and, hence, patterns in the electric field are not information for humans. Due to their different phylogenetic history, then, different species turn to be sensitive and responsive to different patterns, and it is only in relation to a particular kind of organisms that a pattern can be described as information. As Michaels and Carello (1981) point out: "Information is the bridge between an [organism] and its environment and cannot be usefully described without a specification of both" (p. 37-38, emphasis original).

Yet there is a way in which perceptual information relates not only to the species but to the individuals. For example, when an individual occupies a point of observation, the structure of the array at this point is said to contain information regarding this individual-namely, information about her height, her position relative to other objects, her motion, and so on. ${ }^{9}$ To articulate this idea, Stoffregen et al. (2017) have coined the concept of "embodied point of observation." As they describe it:

The embodied point of observation is not a point, in the geometrical sense. It is a region of space, having size, dimensions, and dynamics corresponding to the size, dimensions, and dynamics of the animal. The position and motion of the embodied point of observation are influenced by properties of the animal that inhabits that point of observation. (p. 179)

\footnotetext{
"we need to make a further distinction, between: the environment as it exists for a particular member of a species, a habitat; and the environment as it exists for a particular living animal, an umwelt" (p. 4, emphasis original). Interestingly, this idea is already gestured in Michaels and Carello (1981): "That an animal detects the affordances of an environment means that information is for a species and for an individual" (p. 44).

9 "A sharp distinction will be made between the ambient array at an unoccupied point of observation and the array at a point that is occupied by an observer, human or other. When the position becomes occupied, something very interesting happens to the ambient array: it contains information about the body of the observer" (Gibson 1979/2015, p. 59, emphasis added).
} 
Remarkably, Gibson argues, even though we can separate both kinds of information-information about the environment and information about the animal-for theoretical purposes, the perception (of affordances) implies the detection of both: "Self-perception and environment perception go together" (1979/2015, p. 109). Thus, when Gibsonians speak of perceptual information, it also includes information relative to the organism and its relationship with the surroundings.

Also, according to EP, the perception of affordances requires the detection of a particular kind of informational variables, the 'invariants.' Gibsonians call invariants to the structural patterns of the ambient array that remain constant underlying other transformations. The important aspect to be noted here is that since a transformation is needed to reveal an invariant, the availability of this invariant requires action (Mossio and Taraborelli 2008; Warren 1998; 2005). It follows that the invariants are not available in the structure of the static ambient array; rather they emerge as a consequence of the interaction between an individual organism and its surroundings, and they are available to this particular actor. In this sense, for example, Travieso et al. (2015) appeal to the "the necessity of a dynamical interaction of the perceiver and the environment in order to generate, and be able to pick up [...] the "invariants"”" (p. 386).

For illustration, consider the research in optic flow, this is, the ongoing change of the optic array due to the motion of the agent or the transportation of the objects. Most of the ecological research focuses on the optic flow as a crucial element for visual perception (Lee and Kalmus 1980; Lee and Reddish 1981; Warren 1998). An example of this is the production of motion parallax as a strategy for the perception of depth (Gibson 1950; Favela and Chemero 2016). An animal that moves relative to the objects of the environment produces motion parallax-viz., the continuous and regular transformation of the apparent position of all visible objects from the start point to the end point of the movement. Because the objects closer to the perceiver 'move' faster than those located further away, the perceiver can be aware of the different distances she holds regarding the objects by attending to the different speeds to which 
they 'move' in her optic field. Therefore, by moving about the environment the agent makes available information that enables her to perceive depth.

Another example comes from research in haptic perception-viz. perception by dynamic touch. In well-known experiments on haptic perception, participants are requested to estimate the length of a rod without seeing it, just through haptic information (see, e.g., Shockley, Carello, and Turvey 2004; Turvey and Carello 2011). All these experiments point out to the inertial tensor-that is, the resistance of an object to turn-of the rods as the relevant informational variable required to accomplish the estimation successfully. In the experiments, participants wield and turn the rod, and this wielding and turning make available the inertial tensor. Without turning the rod, then, there is no information relative to the inertial tensor available in the ambient array of the perceiver, which it is to say that there is no information available for the haptic perception of length.

These examples contribute to the view of perception as an active processa process that involves action. For Gibsonians, perception depends on the detection of invariants, but these invariants only turn to be available because of the active exploration of the environment by the organism. ${ }^{10}$ This aspect also stresses the importance of the organisms' history of interactions in perceptual expertise. To successfully accomplish concrete perceptual tasks, organisms have to learn, among other things, how to explore the environment in order to make available the appropriate invariants (Reed 1991; Gibson and Pick 2000).

Taken all these arguments together, we conclude that there is no room in EP to think of perceptual information as being completely divorced from the organisms. Information, in the Gibsonian account, is not just "outside in the

\footnotetext{
${ }^{10}$ To explain the difference between the notion of information invoked by cognitivism and that of EP, some Gibsonians appeal to Runeson's metaphor of a "smart perceptual device" (Runeson 1977; Bingham et al. 1989; Zhu and Bingham 2008; Michaels and Palatinus 2014). Runeson offered the polar planimeter as a metaphor to make the idea of smart perceptual devices more intuitive. The main difference with the cognitivist notion of information is that, in contrast with cognitivist explanations of perception, a smart device detects higher-order information; it does not detect stimuli to be processed and enriched. In the same way that the design of the planimeter allows it to measure the area of a plane through moving over the perimeter, living beings are expected to detect information through acting upon the environment instead of doing mental calculus.
} 
world" (Myin 2016, p. 98), nor is it "intrinsic to the pattern[s]" (Withagen and van der Kamp 2009, p. 210). Rather, although Gibsonians say that information is in the environment, this information is to be understood ecologically, that is, as being dependent on the relationship between the organisms and their econiches.

Before finishing this section, it is important to remark that nothing of what we have said implies a commitment to the idea that information depends on its active use (van Dijk et al. 2015). To say that physical patterns of the ambient array can only be considered information in relation to organisms of a certain kind does not equate to say that these patterns are information only when used by these organisms. Patterns in the electric field are information for sharks, but they do not depend on being used or detected by an individual shark. Also, even though we hold that some informational variables-namely, the invariantsturn to be available because of the agent's exploratory activity, what these invariants inform about is independent of the use the actor makes of them. We elaborate further on these points in section four.

In what follows, we account for the notions of specificity and meaning as used by EP. We argue that describing perceptual information as being specific and meaningful does not imply that this information is contentful.

\section{No need for RECtification: Specificity and meaning without content}

So far, we have addressed the nature of the information invoked by EP. As we have argued, this information cannot be understood as being completely independent of the organisms. This argument, however, does not by itself suffice to dismiss the idea that this information is contentful. After all, both Hutto (2017) and Myin (2016) claim that Gibsonians describe ecological information in terms that belong to the semantic sphere-namely, specificity and meaning. This section aims to deal with this second objection.

The notion of specificity as used in EP refers to a lawful, 1:1 relation between invariant patterns in the ambient array and aspects of the organism- 
environment interaction. ${ }^{11}$ Accordingly, when Gibsonians say that an invariant "specifies" some feature or property of the O-E system, what they mean is that this pattern relates uniquely $(1: 1)$ to this feature or property.

The relation between specification and perception was first articulated by means of the "principle of symmetry" (see Shaw, McIntyre and Mace 1974; Turvey et al. 1981). According to this principle, environment, information, and perception lawfully determine one another so that the environment uniquely relates to the information, which uniquely relates to perception, and perception uniquely relates to information, which uniquely relates to the environment. This symmetry is generally taken to be key to the possibility of direct perception: "because information is specific to an environmental state of affairs and perception is specific to the information, perception is specific to the environmental state of affairs-that is, is direct" (Michaels and Palatinus 2014, p. 21).

Consider, again, the example of optic flow. As we mentioned earlier, the individual's movements in the environment lawfully produce invariant patterns in her sensory array. For instance, as any animal moves toward an object, the image this object projects in her retina lawfully expands, causing the object to expand in her visual field. This is often described by saying that optic flow is centrifugal in the direction of locomotion. By studying the plummeting behavior of gannet birds, Lee and colleagues demonstrated that this centrifugal expansion is of particular relevance for the perceptual guidance of action (see Lee and Kalmus 1980; Lee and Reddish 1981; Lee et al. 2009). As they demonstrated, the ratio of the apparent size of the approaching object to the rate of change of the apparent size of the object-a variable designed "Tau" $(\tau)$-relates $1: 1$ to the time remaining until physical contact between the perceiver and the object. Thus, according to the principle of symmetry described above, an agent can be aware of the time remaining until colliding with an approaching object by

\footnotetext{
11 It is worth mentioning that the notion of law as used by Gibsonians must also be understood at the scale of the O-E systems. As Warren (2005) puts it: "Ecological information is lawful not in the Newtonian sense of being universal in space and time, but in an ecological sense of being regular within an ecological context or constraint" (pp. 242-243).
} 
attending to the ongoing invariant expansion of the object in her visual fieldthe variable specific to time-to-contact.

To explain how agents can modulate their behavior by detecting the invariant patterns available in their sensory array Gibsonians hypothesize that these invariants specify opportunities for interactions or affordances as well. Imagine, for example, that you are driving your car and a dog jumps into the road. Detecting $\tau$ is crucial in this situation, as the time remaining to contact determines whether you can avoid the collision and how. For instance, during a certain period stopping the car before colliding with the dog will be physically possible, and you will be able to do it by gradually adjusting the pressure on the brake pedal. At some point, however, pushing the brake pedal will not suffice to avoid the collision, and the only available option will be to steer the wheel. According to EP, detecting $\tau$ is sufficient for you to perceive these behavioral opportunities, being able to adjust your behavior accordingly.

Now that we have explained what specificity means in the context of EP, the question we need to address is whether describing invariant patterns as being specific equates to say that these patterns are contentful. As we exposed in section two, a process or a state is said to be contentful if it has special conditions of satisfaction-viz. if it can be true or false, veridical or nonveridical, etc., regarding something else. This is not the case of invariants as used by EP. When Gibsonians say that the ratio of expansion of an object in the optic field of an animal specifies time-to-contact they do not mean that this expansion relates to time-to-contact in a way that is susceptible of being semantically evaluated and misrepresenting. Specifying invariant patterns do not relate to the environment or the affordances in any contentful way:

Information in the form of predication can be a truth or a falsehood. A person can misinform in the sense of lie [...]. Information in the form of stimulation (a flowing array of energy) cannot lie-cannot be false in this sense (see below). The light and sound from the environment do not say 
untruths about the environment, only men do that. (Gibson, unpublished material, quoted in Reed 1991, p. 159, emphasis original) ${ }^{12}$

In light of this, and to avoid confusion, we propose that the best way to understand specifying information is to take it as a form of covariant information. Accordingly, the invariant ratio of expansion of the object in the optic array of the animal is said to specify time-to-contact because both features lawfully covary. Hence, although perceptual information is often described as being about the environment (and the affordances), this "aboutness" is to be read in terms of lawful covariation, not in terms of contents. Invariants, so to speak, do not convey anything true or false, veridical or non-veridical, and so on, regarding the environment:

Information about something means only specificity to something. Hence, when we say that information is conveyed by light, or by sound, odor, or mechanical energy, we do not mean that the source is literally conveyed as a copy or a replica. (Gibson 1966, p. 187)

Understanding specification as lawful covariation enables us to think of the structural invariant patterns as being contentless, dissolving the radical enactivists' worries. Accordingly, patterns in the ambient array relate uniquely to the environment and the affordances present within, but this relation does not by itself entail the possibility of semantic misrepresentation.

Furthermore, despite the seemingly problematic image that speaking of information "pick-up" suggests to Hutto and Myin (2013, p. xvi; 2017, p. 86), Gibson (1979/2015, p. 231) was particularly emphatic that specifying information is not information of the kind that can be gathered, stored, transmitted, and manipulated, breaking away with the idea that perceptual systems "pass on" contentful messages. Instead, animals are said to "pick up" information when they attend to the invariant patterns, perceiving the affordances they specify and using them to regulate their actions: "The

12 We are indebted to an anonymous reviewer for calling our attention to this quote. 
information does not consist of signals to be interpreted but of structural invariants which need only to be attended to" (Gibson 1972/2002, p. 79). ${ }^{13}$

Note, again, that we do not claim that structural invariant patterns need to be used to bear information. To see how our proposal differs from the one of van Dijk et al. (2015), consider a situation where perceptual information is not provided visually, but through a vibrotactile sensory substitution device. A famous example of such a device is the enactive torch (Froese et al. 2012). The enactive torch is handled as a flashlight, and it is equipped with distance sensors and a vibrator strapped to the wrist. Once the torch faces some obstacle, namely, an object in the direction of exploration, the vibrator activates, and the characteristics of the vibration depend both on the object explored and the pattern of exploration. The closer I get to an object, for example, the more intensely the device vibrates. As multiple experiments have reported, the patterns of vibration produced by the enactive torch can be used to explore and navigate the surroundings blindfolded (Favela et al. 2018). ${ }^{14}$

Imagine an individual agent that navigates a room by relying exclusively on the vibrations the torch produces when steered in different directions. As she moves the intensity of the vibration varies, and she attends to the different patterns of vibrations to avoid the obstacles she finds. Imagine, however, that while she is moving around the room a loud alarm rings, distracting her attention from the vibrations on her wrist, and causing her to crash into a chair eventually. According to the usage-based account, although the intensity of the vibration kept increasing as the actor approached the chair, because she was not paying attention to them-she was not using them-, the patterns of vibrations didn't contain any information.

As we explained before, this account was introduced as an alternative way to understand perceptual information without appealing to the content-

\footnotetext{
13 "Ecological information cannot be transmitted: it is ambient and available, not something put over a channel; it is something to be detected or used (or not) in regulating action [...] Information pick up is not a process of "internalizing" information" (Reed 1996, p. 155).

14 For more examples of sensory substitution devices applied to research in ecological psychology see Lobo et al. $(2014,2018)$
} 
involving relations allegedly implied by the notion of specificity. Yet if our analysis is correct specifying information is not information-as-content, and hence there is no obvious explanatory gain in giving up specificity from the theory. Moreover, if those who think that specificity is a necessary condition for direct perception (see, e.g., Michaels and Carello 1981; Turvey et al. 1981; Michaels and Palatinus 2014; Stoffregen et al. 2017) are on the right track, by giving up specificity we run the risk of giving up direct perception too. ${ }^{15}$

We propose, by contrasts, that because the intensity of the vibration lawfully covaries with the proximity of the obstacle the former can be considered information about the latter, and it is so independently of whether the actor detects or uses it. This is, although the differences in the intensity of vibration are a consequence of the exploratory actions of the agent-namely, they are caused by the fact that she gets closer to the chair-they need not be used by her to bear information about the proximity. Compare this case with a situation in which the patterns of vibrations have no relation with the patterns of exploration of the agent-for instance, a broken device that vibrates to the same intensity independently of the distance between the agent and the chair. In this second case, the patterns of vibration cannot inform about proximity, but this is so independently of whether the agent tries to use them to guide her movements. As we see it, information is contingent on the lawful covariation between patterns in the sensory array and features of the O-E relation, but not on being actively used or perceived by an agent. This reading is more accurate to the Gibsonian approach and shows that there is no real conflict between the information as conceived by REC and the information as conceived by Gibsonians.

\footnotetext{
15 It is worth mentioning that some Gibsonians have proposed that the concept of information needs to be expanded so as to include variables that do not relate to the environment in a lawful (1:1) manner (Chemero 2009; Golonka 2015). According to this idea, non-specifying variables, this is, variables that are contingent on conventions or reliably enough regularities, can support direct perception as well. Whether or not this hypothesis is tenable is not an issue we can address in this paper. Our claim, instead, is that the risk of conflating specifying information with information-as-content is not a good reason to abandon specificity.
} 
The previous discussion allows us to introduce another critique of Hutto (2017) and Myin (2016): the notion of meaning as used in EP. According to Hutto and Myin, the fact that Gibsonians describe perceptual information as being meaningful reveals an underlying commitment to the idea that this information bears content. The question is, then: Can EP hold that information is meaningful and contentless at the same time?

The notion of meaning as used in EP is to be related to the idea that perception is primarily for the control of action. As Gibson (1974/1982) explicates, "active perception is controlled by a search for the affordances of the environment of the environment" (p. 388). According to this view, the exploratory activity of the agent is always purposeful, meaning that when agents explore the environment the information they detect is taken in relation to a goal. This idea, combined with the view that information specifies-in the sense explained above-affordances or behavioral opportunities lead to the claim that information is meaningful for the organisms. Meaning, as used by Gibsonians, is thus orthogonal to semantics, as it is to be understood in terms of the affordances an econiche offers to a particular organism: "the meaning or value of a thing consists of what it affords" (Gibson 1967/1982, p. 407).16

An important aspect to be noted is that perceptual information is said to be meaningful for an organism, and not meaningful per se. The reason is that the affordances a particular informational variable specifies depend on the conjunction of the agent and the physical properties of the environment. Affordances imply "the complementarity of the animal and the environment" (Gibson 1979/2015, p. 119). It follows that different organisms, this is, organisms with different body features, different action capabilities, different history of interactions, and so on, will perceive different affordances while detecting the same information. When you see the mug that is on your desk, for example, you perceive the possibility of grasping it, but this action is possible only because you have opposable thumbs and because the relation between the

\footnotetext{
16 Costall (2012) has coined the notion of "use-meaning" to distinguish the ecological notion of meaning from semantic meaning and the meaning associated with representations.
} 
size of your hand and the size of the mug is adequate. An animal that does not have these physical features will not perceive the possibility of grasping the mug (Warren 1984; Fajen 2007).

Thus, meaning as used in EP is not "inherent to the natural world" (Myin 2016, p. 98), nor does it need to be constructed or computed by mental processes. Rather, as Richardson et al. (2008) write, "meaning can be understood and studied as an objective and real property of an O-E system" (p. 168). Perceptual information is meaningful in so far as it specifies opportunities for interaction to an actor, without any assumption that it carries content.

\section{Conclusion}

How radical is EP? According to radical enactivists, the way Gibsonians describe perceptual information leads them to positions that are akin to the ones offered by representationalists, locating informational contents in the outside world instead of in the head (Myin 2016; Hutto 2017; Hutto and Myin 2017; see also van Dijk, Withagen, and Bongers 2015). In summary, they find three main issues in the Gibsonian approach. First, the idea that perception requires picking up information from the outside world. Second, the idea that this information specifies or is about the environment and the affordances present within. And, third, that this information is meaningful. In light of this, radical enactivists conclude that EP is not radical enough as it stands, and that it needs to be "RECtified"-viz., "sanitized" of its representational commitments—if it is to be included in a genuine non-representational approach to cognitive science.

Contrary to this view, we have argued that the notions of information, specificity, and meaning, if properly understood, do not entail a commitment to the existence of informational content in the world, and, thus, that EP is not in conflict with the principles of the radical forms of embodied cognitive science.

First, we have argued that perceptual information as conceived by EP is to be related to the organisms that inhabit a particular econiche. This relation, however, can be understood in different ways depending on whether we 
understand the organism as species or as an individual. Regarding the first interpretation, we have argued that different physical patterns require specialized perceptual systems capable of detecting them, and, then, that a pattern that is informational for a kind of organisms may not be so for another. Yet there is a sense in which information is related to individuals as well. According to Gibsonians, perception requires the detection of invariants-viz., structural patterns that remain constant underlying other transformation. Because an invariant can only be detected against particular transformation, invariants as key informational variables only turn to be available through the active exploration of the environment by the agent. In the absence of particular organism-environment interactions, invariants are not available in the environment to be detected. Both reasons together cast doubts upon the idea that perceptual information is simply outside in the world, independently of the organisms.

After clarifying the nature of the perceptual information posited by EP, we have discussed whether describing this information as being specific and meaningful entails that this information is of a contentful kind. As we have argued, the notion of specificity refers to the lawful, 1:1 relation between invariant patterns in the ambient array and aspects of the organismenvironment interaction. As such, specificity can best be understood as lawful covariation, without any assumption that it carries content. Invariants covary with the environment and the affordances present in it, but they do not convey anything true or false, veridical or non-veridical, and so on, about them. Finally, we have explained that the notion of meaning as used in EP is to be related to the affordances. Perceptual information, hence, is said to be meaningful for an agent or an organism because it affords certain opportunities for interaction to her, but this meaning is orthogonal to semantics.

In light of these arguments, we conclude that EP is radical enough and that it is apt to be included in a full-blown post-cognitivist approach to cognition. 


\section{Funding}

Heras-Escribano's contribution was partially funded by a Juan de la CiervaFormación Research Fellowship and the research project FFI2016-80088-P of the Spanish Ministry of Economy, the Unidad de Excelencia Filolab (Universidad de Granada) and a 2018 Leonardo Grant for Researchers and Cultural Creators, BBVA Foundation. The Foundation accepts no responsibility for the opinions, statements and contents included in the project and/or the results thereof, which are entirely the responsibility of the authors.

\section{Acknowledgments}

We thank Nick Brancazio, Frank Faries, Paco Calvo, Tony Chemero, Manuel de Pinedo, Daniel D. Hutto, Michael Kirchhoff and three anonymous reviewers for fruitful suggestions on earlier versions of this paper.

\section{References}

Bingham, G. P., Schmidt, R. C., and Rosenblum, L. D. (1989). Hefting for a maximum distance throw: A smart perceptual mechanism. Journal of Experimental Psychology: Human Perception and Performance, 15(3), 507-528. https://doi.org/10.1037//0096-1523.15.3.507

Baggs, E., and Chemero, A. (2018). The third sense of environment. https://doi.org/10.31234/osf.io/sxmrz

Chemero, A. (2009). Radical Embodied Cognitive Science. Cambridge, Mass.: MIT Press.

Costall, A. (2012). Canonical affordances in context. Avant: Trends in Interdisciplinary Studies, 3(2), 85-93.

Fajen, B. R. (2005). Perceiving possibilities for action: On the necessity of calibration and perceptual learning for the visual guidance of action. Perception, 34(6), 717-740. https://doi.org/10.1068/p5405

Fajen, B. R. (2007). Affordance-based control of visually guided action. Ecological Psychology, 19(4), 383-410. 
Favela, L. H., and Chemero, A. (2016). The animal-environment system. In Y. Coelllo and M. H. Fischer (Eds.), Foundations of Embodied Cognition: Volume 1: Perceptual and Emotional Embodiment (pp. 59-74). New York, NY: Routledge.

Favela, L. H., Riley, M. A., Shockley, K., and Chemero, A. (2018). Perceptually equivalent judgments made visually and via haptic sensory-substitution devices. Ecological Psychology, 30(4), 326-345. https://doi.org/10.1080/10407413.2018.1473712

Fodor, J. A., and Pylyshyn, Z. W. (1981). How direct is visual perception? Some reflections on Gibson's "ecological approach." Cognition, 9(2), 139-196. https://doi.org/10.1016/0010-0277(81)90009-3

Froese, T., McGann, M., Bigge, W., Spiers, A., and Seth, A. K. (2012). The Enactive Torch: A New Tool for the Science of Perception. IEEE Transactions on Haptics, 5(4), 365-375. https://doi.org/10.1109/TOH.2011.57

Fultot, M., Nie, L., and Carello, C. (2016). Perception-action mutuality obviates mental construction. Constructivist Foundations, 11(2), 298-307.

Gibson, J. J. (1950). The Perception of the Visual World. Westport, Conn.: Greenwood Press.

Gibson, J. J. (1961). Ecological optics. Vision Research, 1(3), 253-262. https://doi.org/10.1016/0042-6989(61)90005-0

Gibson, J. J. (1966). The Senses Considered as Perceptual Systems. Westport, Conn.: Greenwood Press.

Gibson, J. J. (1968/1982). Notes on affordances. In E. Reed and R. Jones (Eds.), Reasons for Realism. Selected Essays of James J. Gibson (pp. 401-418). Hillsdale, NJ: Lawrence Erlbaum Associates.

Gibson, J. J. (1972/2002). A theory of direct visual perception. In A. Noë and E. Thompson (Eds.), Vision and Mind: Selected Readings in the Philosophy of Perception (pp. 77-89). Cambridge, Mass.: MIT Press.

Gibson, J. J. (1974/1982). Notes on action. In E. Reed and R. Jones (Eds.), Reasons for Realism. Selected Essays of James J. Gibson (pp. 385-392). Hillsdale, NJ: Lawrence Erlbaum Associates.

Gibson, J. J. (1979/2015). The Ecological Approach to Visual Perception. New York, NY: Psychology Press.

Gibson, E. J., and Pick, A. D. (2000). An Ecological Approach to Perceptual Learning and Development. New York, NY: Oxford University Press. 
Glotzbach, P. A., and Heft, H. (1982). Ecological and phenomenological contributions to the psychology of perception. Noûs, 16(1), 108-121. https://doi.org/10.2307/2215421

Golonka, S. (2015). Laws and conventions in language-related behaviors. Ecological Psychology, 27(3), 236-250. https://doi.org/10.1080/10407413.2015.1068654

Golonka, S., and Wilson, A. D. (2016). Ecological representations. BioRxiv, 058925. https://doi.org/10.1101/058925

Grice, H. P. (1957). Meaning. The Philosophical Review, 66(3), 377. https://doi.org/10.2307/2182440

Heras-Escribano, M., and de Pinedo, M. (2016). Are affordances normative? Phenomenology and the Cognitive Sciences, 15(4), 565-589. https://doi.org/10.1007/s11097-015-9440-0

Hutto, D. D. (2017). REC: Revolution effected by clarification. Topoi, 36(3), 377-391. https://doi.org/10.1007/s11245-015-9358-8

Hutto, D. D., and Myin, E. (2013). Radicalizing Enactivism : Basic Minds Without Content. Cambridge, Mass.: MIT Press.

Hutto, D. D., and Myin, E. (2017). Evolving Enactivism: Basic Minds Meet Content. Cambridge, Mass.: MIT Press.

Jacob, P. (1997). What Minds Can Do: Intentionality in a Non-Intentional World. Cambridge, UK: Cambridge University Press.

Lee, D. N., and Kalmus, H. (1980). The optic flow field: Thefoundation of vision [and Discussion]. Philosophical Transactions of the Royal Society B: Biological Sciences, 290(1038), 169-179. https://doi.org/10.1098/rstb.1980.0089

Lee, D. N (2009). General Tau Theory: Evolution to date. Perception, 38(6), 837-858. https://doi.org/10.1068/pmklee

Lee, David N., and Reddish, P. E. (1981). Plummeting gannets: A paradigm of ecological optics. Nature, 293(5830), 293-294. https://doi.org/10.1038/293293a0

Lobo, L., Travieso, D., Barrientos, A., and Jacobs, D. M. (2014). Stepping on obstacles with a sensory substitution device on the lower leg: Practice without vision is more beneficial than practice with vision. PLOS ONE, 9(6), e98801. https://doi.org/10.1371/journal.pone.0098801

Lobo, L., Travieso, D., Jacobs, D., Rodger, M. and Craig, C. (2018). Sensory substitution: Using a vibrotactile device to orient and walk to targets. Journal of Experimental Psychology 24(1), 108-124. 
Lombardo, T. J. (1987). The Reciprocity of Perceiver and Environment: The Evolution of James J. Gibson's Ecological Psychology. Hillsdale, N.J: L. Erlbaum Associates.

Marr, D. (1982). Vision: A Computational Investigation into the Human Representation and Processing of Visual Information. Cambridge, Mass: MIT Press.

Michaels, C. F., and Carello, C. (1981). Direct Perception. Englewood Cliffs, N.J: PrenticeHall.

Michaels, C. F., and Palatinus, Z. (2014). A ten commandments for ecological psychology. In L. Shapiro (Ed.), The Routledge Handbook of Embodied Cognition. (pp. 19-28). New York, NY: Routledge.

Millikan, R. G. (1984). Language, Thought, and other Biological Categories: New Foundations for Realism. Cambridge, Mass.: MIT Press.

Millikan, R. G. (2005). Language: A Biological Model. Oxford, UK: Oxford University Press.

Mossio, M., and Taraborelli, D. (2008). Action-dependent perceptual invariants: From ecological to sensorimotor approaches. Consciousness and Cognition, 17(4), 13241340. https://doi.org/10.1016/j.concog.2007.12.003

Myin, E. (2016). Perception as something we do. Journal of Consciousness Studies, 23(56), 80-104.

Reed, E. (1991). James Gibson's ecological approach to cognition. In A. Costall and A. Still (Eds.), Cognitive psychology in question (pp. 142-173). New York, NY: St Martin's Press.

Reed, E. (1996). Encountering the World: Toward an Ecological Psychology. New York: Oxford University Press.

Richardson, M. J., Shockley, K., Fajen, B. R., Riley, M. A., and Turvey, M. T. (2008). Ecological Psychology: Six principles for an embodied-embedded approach to behavior. In P. Calvo and A. Gomila (Eds.), Handbook of Cognitive Science (pp. 159187). New York, NY: Elsevier.

Runeson, S. (1977). On the possibility of "smart" perceptual mechanisms. Scandinavian Journal of Psychology, 18(1), 172-179.

Shannon, C. E. (1948). A mathematical theory of communication. The Bell System Technical Journal, 27(3), 379-423. https://doi.org/10.1002/j.15387305.1948.tb01338.x

Shaw, R., McIntyre, M., and Mace, W. (1974). The role of symmetry in event perception. In R. B. Macleod and H. L. Pick (Eds.), Perception: Essays in Honor of James J. Gibson. (pp. 317-317). London, UK: Cornell University Press. 
Shockley, K., Carello, C., and Turvey, M. T. (2004). Metamers in the haptic perception of heaviness and moveableness. Perception \& Psychophysics, 66(5), 731-742. https://doi.org/10.3758/BF03194968

Stoffregen, T. A., Mantel, B., and Bardy, B. G. (2017). The senses considered as one perceptual system. Ecological Psychology, 29(3), 165-197. https://doi.org/10.1080/10407413.2017.1331116

Thompson, E. (2007). Mind in Life: Biology, Phenomenology, and the Sciences of Mind. Harvard, US: Harvard University Press.

Travieso, D., Gomila, A., and Lobo, L. (2014). From systematicity to interactive regularities: Grounding cognition at the sensorimotor level. In P. Calvo and J. Symmons (Eds.), The Architecture of Cognition (pp. 371-396). Cambridge, Mass.: MIT Press.

Turvey, M. T., and Carello, C. (2011). Obtaining information by dynamic (effortful) touching. Philosophical Transactions of the Royal Society B: Biological Sciences, 366(1581), 3123-3132. https://doi.org/10.1098/rstb.2011.0159

Turvey, M. T. (2013). Ecological perspective on perception-action: What kind of science does it entail? In W. Prinz, M. Beisert, and A. Herwig (Eds.), Action Science (pp. 138170). Cambridge, Mass.: MIT Press.

Turvey, M.T., Shaw, R. E., Reed, E. S., and Mace, W. M. (1981). Ecological laws of perceiving and acting: In reply to Fodor and Pylyshyn (1981). Cognition, 9(3), 237304. https://doi.org/10.1016/0010-0277(81)90002-0

Ullman, S. (1980). Against direct perception. Behavioral and Brain Sciences, 3(3), 373381. https://doi.org/10.1017/S0140525X0000546X

van Dijk, L., Withagen, R., and Bongers, R. M. (2015). Information without content: A Gibsonian reply to enactivists' worries. Cognition, 134.

Varela, F. J., Thompson, E., and Rosch, E. (1991). The Embodied Mind: Cognitive Science and Human Experience. Cambridge, Mass.: MIT Press.

Warren, W. H. (1984). Perceiving affordances: Visual guidance of stair climbing. Journal of Experimental Psychology: Human Perception and Performance, 10(5), 683-703. https://doi.org/10.1037/0096-1523.10.5.683

Warren, W. H. (1998). Visually controlled locomotion: 40 years later. Ecological Psychology, 10(3-4), 177-219. https://doi.org/10.1080/10407413.1998.9652682

Warren, W. H. (2005). Direct perception: The view from here. Philosophical Topics, 33(1), 335-361. https://doi.org/10.5840/philtopics200533113 
Withagen, R., and van der Kamp, J. (2010). Towards a new ecological conception of perceptual information: Lessons from a developmental systems perspective. Human Movement Science, 29(1), 149-163. https://doi.org/10.1016/j.humov.2009.09.003

Zhu, Q., and Bingham, G. P. (2008). Is hefting to perceive the affordance for throwing a smart perceptual mechanism? Journal of Experimental Psychology: Human Perception and Performance, 34(4), 929-943. https://doi.org/10.1037/0096-1523.34.4.929 